\title{
Structures of copper(II) 2-chlorobenzoate monohydrate and copper(II) 3,5-dichlorobenzoate trihydrate
}

\author{
Jana Medveckáa, Jozef Halaška ${ }^{a}$, Klaudia Jomovab ${ }^{b}$ Jan Moncola \\ ${ }^{a}$ Faculty of Chemical and Food Technology, Slovak Technical University, \\ Radlinského 9, SK-812 37, Bratislava, Slovakia \\ ${ }^{b}$ Department of Chemistry, Faculty of Natural Sciences, Constantine The Philosopher University, \\ SK-949 74 Nitra, Slovakia \\ jan.moncol@stuba.sk
}

\begin{abstract}
The crystal structures of the title compounds, $\left[\mathrm{Cu}_{2}(\mu 2-2-\mathrm{Clbz})_{4}\left(\mathrm{H}_{2} \mathrm{O}\right)_{2}\right]$ (1) and $[\mathrm{Cu}(3,5-$ $\left.\left.\mathrm{Cl}_{2} \mathrm{bz}\right)_{2}\left(\mathrm{H}_{2} \mathrm{O}\right)_{3}\right](2)$, have been redetermined at $150 \mathrm{~K}$. The compound 1 forms dimeric complex where two $\mathrm{Cu}^{2+}$ cations are bridged through four 2-chlorobenzoate ligands. The $\mathrm{Cu}^{2+}$ ion in $\mathbf{1}$ is pentacoordinated by four oxygen atoms of bridging 2-chlorobenzoate ligands and one coordinated water molecule. The compound 2 forms mononuclear complex, where the $\mathrm{Cu}^{2+}$ ion is pentacoordinated by two oxygen atoms of monodentate 3,5-dichlorobenzoate ligands and three coordinated water molecule. Both complexes are connected through $\mathrm{O}-\mathrm{H} \cdots \mathrm{O}$ hydrogen bonds into frameworks. The $\pi-\pi$ stacking interactions are also observed in crystal structure of 2 .
\end{abstract}

Keywords: copper, X-ray, chlorobenzoate, dichlorobenzoate, hydrogen bonds

\section{Introduction}

Different benzoates, especially salicylates and fenamates are known to play an important role in human medicine (Sorenson, 1976; Weder et al. 2002). Our effort in this field has been targeted to halogeno- and dihalogeno- substituted benzoate complexes. The aim of this paper is to report an X-ray structures of the dinuclear complex $\left[\mathrm{Cu}(2-\mathrm{Clbz})_{2}\left(\mathrm{H}_{2} \mathrm{O}\right)\right]_{2}$ and mono- nuclear complex $\left[\mathrm{Cu}\left(3,5-\mathrm{Cl}_{2} \mathrm{bz}\right)_{2}\left(\mathrm{H}_{2} \mathrm{O}\right)_{3}\right]$. These complexes were previously prepared and published (Kawata et al., 1992; Wołodkiewicz et al., 1998). Object of our study is mention to conditions of preparation of reported complexes and re-determined of obtained complexes at $150 \mathrm{~K}$ because published results don't contain hydrogen bond networks and $\pi-\pi$ stacking interactions in crystal structures of both complexes.

Tab. 1. Experimental details.

\begin{tabular}{lll}
\hline & $\mathbf{1}$ & $\mathbf{2}$ \\
\hline Chemical formula & $\mathrm{C}_{28} \mathrm{H}_{20} \mathrm{Cl}_{4} \mathrm{Cu}_{2} \mathrm{O}_{10}$ & $\mathrm{C}_{14} \mathrm{H}_{12} \mathrm{Cl}_{4} \mathrm{CuO}_{7}$ \\
$M_{\mathrm{r}}$ & 785.32 & 497.58 \\
Crystal system, space group & Monoclinic, $P 2_{1} / c$ & Monoclinic, $P 2_{1} / c$ \\
Temperature (K) & 150 & 150 \\
$a, b, c(\AA)$ & $7.1940(4), 19.5140(16), 11.5060(4)$ & $16.8280(4), 8.2930(7), 13.4700(14)$ \\
$\beta\left(^{\circ}\right)$ & $113.636(3)$ & $103.882(4)$ \\
$V\left(\AA^{3}\right)$ & $1479.75(16)$ & $1824.9(2)$ \\
$Z$ & 2 & 4 \\
Radiation type & Mo $K_{\alpha}$ & Mo $K_{\alpha}$ \\
$\mu\left(\right.$ mm $\left.^{-1}\right)$ & 1.856 & 1.817 \\
Crystal size $($ mm) & $0.23 \times 0.20 \times 0.20$ & $0.35 \times 0.31 \times 0.15$ \\
Diffractometer & Bruker Kappa APEXII CCD & Bruker Kappa APEXII CCD \\
Absorption correction & Multi-scan SADABS (Bruker, 2008) & Multi-scan SADABS (Bruker, 2008) \\
$T_{\min }, T_{\text {max }}$ & $0.675,0.836$ & $0.569,0.772$ \\
No. of measured, independent and observed & $13697,2976,2410$ & $14578,3697,2991$ \\
{$[I>2 \sigma(I)]$ reflections } & & \\
$R_{\text {int }}$ & 0.0404 & 0.0379 \\
$R\left[F^{2}>2 \sigma\left(F^{2}\right)\right], w R\left(F^{2}\right), S$ & $0.0366,0.0785,1.091$ & $0.0305,0.0649,1.068$ \\
No. of reflections & 2976 & 3697 \\
No. of parameters & 199 & 235 \\
$\left.\Delta\rangle_{\max }, \Delta\right\rangle_{\min }\left(\mathrm{e} \AA^{-3}\right)$ & $0.463,-0.594$ & $0.360,-0.438$ \\
$\mathrm{CCDC}$ & 869080 & 869081 \\
\hline
\end{tabular}




\section{Experimental}

\section{Synthesis}

A water solution of copper(II) acetate monohydrate $(0.200 \mathrm{~g}, 1 \mathrm{mmol}$ in $40 \mathrm{ml}$ of water $)$ was stirred with nicotinamide $(0.061 \mathrm{~g}, 0.5 \mathrm{mmol})$ for 1 or $\mathrm{N}, \mathrm{N}$ diethylnicotinamide $(0.084 \mathrm{ml}, 0.5 \mathrm{mmol})$ for 2 and then the 2-chlorobenzoic acid $(0.313 \mathrm{~g}, 2 \mathrm{mmol})$ for 1 or 3,5-dichlorobenzoic acid $(0.382 \mathrm{~g}, 2 \mathrm{mmol})$ for 2 was added. These mixtures were stirred for 1 day resulting in a light green (1) or turquoise-blue (2) suspensions. The main products of $\mathbf{1}$ or $\mathbf{2}$ were filtered off and dried at ambient temperature and a green (1) or turquoise (2) mother liquid were left crystallization. Green block crystals of $\mathbf{1}$ and turquoise plate crystals of $\mathbf{2}$ were separated from the mother liquor after several weeks. Powders were obtained from systems without added neutral ligand too.

\section{X-ray Crystallography}

Crystal data and conditions of data collection and refinement are reported in Table 1. Data collection and cell refinement were carried out using diffractometer Bruker Kappa APEXII CCD (Bruker, 2008) at $150 \mathrm{~K}$ with graphite monochromated Mo $\mathrm{K}_{\alpha}$ radiation. The semi-empirical absorption corrections were applied the using multi-scan method. The structures were solved by direct methods using SIR-97 (Altomare et al., 1999) or SHELXS-97 (Sheldrick, 2008) and refined by the full-matrix leastsquares procedure with SHELXL-97 (Sheldrick, 2008). Geometrical analyses were performed with SHELXL-97. The structures were drawn with XP in SHELXTL (Sheldrick, 2008).

\section{Results and discussion}

The principle structure features of $\left[\mathrm{Cu}_{2}(2-\right.$ Clbz $\left.)_{4}\left(\mathrm{H}_{2} \mathrm{O}\right)_{2}\right](\mathbf{1})$ are illustrated in Fig. 1 and selected bond distances and angles are given in Table 2. The compound $\mathbf{1}$ crystallizes in the monoclinic system (space group $\mathrm{P} 2_{1} / \mathrm{c}$ ). The crystal structure of $\mathbf{1}$ at $295 \mathrm{~K}$ has already been reported (Kawata et al., 1992) and now it is re-determined at $150 \mathrm{~K}$. The complex has been prepared by a different method (see experimental section) as reported previously (Kawata et al., 1992). The crystal structure of 1 consists of centrosymmetric tetracarboxylato-bridged dimmers $\left[\mathrm{Cu}(2-\mathrm{Clbz})_{2}\left(\mathrm{H}_{2} \mathrm{O}\right)\right]_{2}$, where the $\mathrm{Cu}$... Cu separation is 2.5934(6) $\AA$. This molecular structure is typical of dimeric copper(II) carboxylate complexes, where the $\mathrm{Cu} \cdot \mathrm{Cu}$ distances are in the range 2.56-2.88 A (Melnik et al., 1998; Sundberg et al., 1996). The $\tau$ value (Addison et al., 1984) of $0.0^{\circ}$ for the copper atom is typical for square pyramidal geometry. The basal plane consists of four oxygen atoms O1, O2 $2^{\mathrm{i}}$, O3 and O4 ${ }^{\mathrm{i}}$ [Symmetry code: (i) $-x+2,-y,-z+2$ ] at distances of 1.952(2)-1.985(2) А. The apical site is occupied by the oxygen atom $(\mathrm{O} 1 \mathrm{~W})$ from coordinated water molecules. The apical $\mathrm{Cu}-\mathrm{O} 1 \mathrm{~W}$ bond length of 2.134(2) $\AA$, and the $\mathrm{Cu}-\mathrm{O}_{\text {carb }}$ bond lengths are in good agreement with those found in the other dimeric copper(II) carboxylate complexes (Melnik et al., 1998; Sundberg et al., 1996). The copper atom is displaced from the squares plane defined by the basal atoms toward the apical oxygen atom by $0.190(1) \AA$. The sum of the bond distances $(\Sigma \mathrm{Cu}-\mathrm{L}) 11.29 \AA$ in $\mathbf{1}$ (the half value of the $\mathrm{Cu} \cdots \mathrm{Cu}$ distance is also included in the sum) agrees will with the values reported for known dimeric structures with the $\mathrm{CuO}_{4} \mathrm{O}$ chromophores (Melnik et al., 1998). The values of angles O1-C1-O2 [124.5(3) $\AA]$ and O3-C8-O4 [124.4(3) $\AA$ ] are in the range $11.6-132.0^{\circ}$ found for tetracarboxylato dimers with $\mathrm{CuO}_{4} \mathrm{O}$ chromophores (Sundberg et al., 1996).

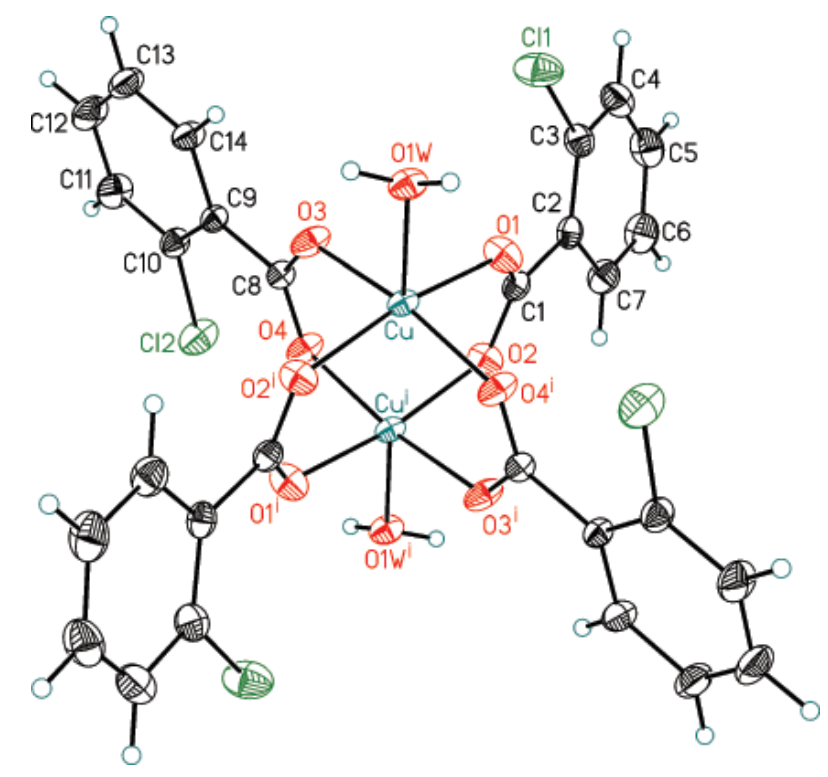

Fig. 1. Perspective view of $\mathbf{1}$, with the atom numbering scheme. Thermal ellipsoids are drawn at the $30 \%$ probability level. [Symmetry code: (i) $-x+2,-y,-z+2$ ].

The principal structural feature and atom numbering scheme of complex $\mathbf{2}$ are depicted in Fig. 2 and selected bond distances and angles are listed in Table 2. The compound $\mathbf{2}$ crystallizes in the monoclinic system with space group $\mathrm{P} 2{ }_{1} / \mathrm{c}$ and its structure at $295 \mathrm{~K}$ has already been reported (Wołodkiewicz et al., 1998). This report describes re-determination at $150 \mathrm{~K}$ complex from crystal prepared by a different method (see experimental section) as reported previously (Wołodkiewicz et al., 1998). The independent part of structure of 2 consists of $\left[\mathrm{Cu}\left(3,5-\mathrm{Cl}_{2} \mathrm{bz}\right)_{2}\left(\mathrm{H}_{2} \mathrm{O}\right)_{3}\right]$ molecule elongated 
Table 2. Selected geometric parameters $(\AA \stackrel{\circ}{\circ})$.

\begin{tabular}{|c|c|c|c|}
\hline \multicolumn{4}{|l|}{1} \\
\hline $\mathrm{Cu}-\mathrm{O} 3$ & $1.952(2)$ & $\mathrm{Cu}-\mathrm{O} 2^{\mathrm{i}}$ & $1.985(2)$ \\
\hline $\mathrm{Cu}-\mathrm{O} 4^{\mathrm{i}}$ & $1.958(2)$ & $\mathrm{Cu}-\mathrm{O} 1 \mathrm{~W}$ & $2.134(2)$ \\
\hline $\mathrm{Cu}-\mathrm{O} 1$ & $1.960(2)$ & $\mathrm{Cu}-\mathrm{Cu}^{\mathrm{i}}$ & $2.5934(6)$ \\
\hline $\mathrm{O} 3-\mathrm{Cu}-\mathrm{O} 4^{\mathrm{i}}$ & $168.78(8)$ & $\mathrm{O} 3-\mathrm{Cu}-\mathrm{O} 1 \mathrm{~W}$ & $94.15(8)$ \\
\hline $\mathrm{O} 3-\mathrm{Cu}-\mathrm{O} 1$ & $90.33(10)$ & $\mathrm{O} 4-\mathrm{Cu}-\mathrm{O} 1 \mathrm{~W}$ & $96.97(8)$ \\
\hline 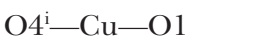 & $89.92(10)$ & $\mathrm{O} 1-\mathrm{Cu}-\mathrm{O} 1 \mathrm{~W}$ & $96.11(8)$ \\
\hline $\mathrm{O} 3-\mathrm{Cu}-\mathrm{O} 2^{\mathrm{i}}$ & $90.67(10)$ & $\mathrm{O} 2^{\mathrm{i}}-\mathrm{Cu}-\mathrm{O} 1 \mathrm{~W}$ & $94.96(8)$ \\
\hline $\mathrm{O} 4^{\mathrm{i}}-\mathrm{Cu}-\mathrm{O} 2^{\mathrm{i}}$ & $86.94(10)$ & $\mathrm{O} 1-\mathrm{Cu}-\mathrm{O} 2^{\mathrm{i}}$ & $168.78(9)$ \\
\hline \multicolumn{4}{|l|}{2} \\
\hline $\mathrm{Cu} 1-\mathrm{O} 13$ & $1.911(2)$ & $\mathrm{Cu} 1-\mathrm{O} 1 \mathrm{~W}$ & $1.968(2)$ \\
\hline $\mathrm{Cu} 1-\mathrm{O} 12$ & $1.944(2)$ & $\mathrm{Cu} 1-\mathrm{O} 3 \mathrm{~W}$ & $2.291(2)$ \\
\hline $\mathrm{Cu} 1-\mathrm{O} 2 \mathrm{~W}$ & $1.966(2)$ & & \\
\hline $\mathrm{O} 13-\mathrm{Cu} 1-\mathrm{O} 12$ & $177.29(7)$ & $\mathrm{O} 2 \mathrm{~W}-\mathrm{Cu} 1-\mathrm{O} 1 \mathrm{~W}$ & $168.29(8)$ \\
\hline $\mathrm{O} 13-\mathrm{Cu} 1-\mathrm{O} 2 \mathrm{~W}$ & $91.93(7)$ & $\mathrm{O} 13-\mathrm{Cu} 1-\mathrm{O} 3 \mathrm{~W}$ & $83.08(7)$ \\
\hline $\mathrm{O} 12-\mathrm{Cu} 1-\mathrm{O} 2 \mathrm{~W}$ & $90.22(7)$ & $\mathrm{O} 12-\mathrm{Cu} 1-\mathrm{O} 3 \mathrm{~W}$ & $95.27(7)$ \\
\hline $\mathrm{O} 13-\mathrm{Cu} 1-\mathrm{O} 1 \mathrm{~W}$ & $89.27(7)$ & $\mathrm{O} 2 \mathrm{~W}-\mathrm{Cu} 1-\mathrm{O} 3 \mathrm{~W}$ & $89.90(7)$ \\
\hline $\mathrm{O} 12-\mathrm{Cu} 1-\mathrm{O} 1 \mathrm{~W}$ & $88.96(7)$ & $\mathrm{O} 1 \mathrm{~W}-\mathrm{Cu} 1-\mathrm{O} 3 \mathrm{~W}$ & $101.80(7)$ \\
\hline
\end{tabular}

Symmetry code: (i) $-x+2,-y,-z+2$.

tetragonal-pyramidal coordination polyhedron around $\mathrm{Cu}$ atom. The coordination sphere of copper(II) atom in trans-basal plane is formed by two 3,5-dichlorobenzoate anions bonded via $\mathrm{O} 12$ and O13 carboxylate oxygen atoms $[\mathrm{Cu}-\mathrm{O} 12$ distance is of 1.944(2) $\AA$ and Cu-O13 is of 1.911(2) $\AA$ ] and two water molecules bonded via $\mathrm{O} 1 \mathrm{~W}$ and $\mathrm{O} 2 \mathrm{~W}$ atoms [Cu-O1W distance is of 1.968(2) $\AA$ and $\mathrm{Cu}-\mathrm{O} 2 \mathrm{~W}$ is of $1.966(2) \AA]$. Third water molecule is bonded in an apical position of square-pyramidal polyhedron via $\mathrm{O} 3 \mathrm{~W}$ donor atom with slightly longer bond distance $\mathrm{Cu}-\mathrm{O} 3 \mathrm{~W}$ of 2.291(2) A. The tetragonality parameter value $(\tau)$ (Addison et al., 1984) is about 0.15 indicating nearly ideal square-pyramidal coordination sphere. The basal planes of the neighbor- ing complex molecules are coplanar and the distance between the basal planes is 3.518(1) $\AA$. Moreover, the water molecules in basal position $\mathrm{O} 1 \mathrm{~W}$ form strong hydrogen bonds (Fig. 2 and Table 3) with pairs of carboxylate oxygen atoms O22 and O23 $\left[\mathrm{O} 1 \mathrm{~W}-\mathrm{H} 1 \mathrm{~W} \cdots \mathrm{O} 22^{\mathrm{ii}}\right.$ and $\mathrm{O} 1 \mathrm{~W}-\mathrm{H} 2 \mathrm{~W} \cdots \mathrm{O} 23^{\mathrm{ii}}$ (Symmetry codes: (ii) $-x+1,-y+1,-z+2$ ) with $\mathrm{O} \cdots \mathrm{O}$ distances of 2.784(2) and 2.703(2) A, respectively] which causes that the $\mathrm{Cu} \cdot \mathrm{Cu}^{\mathrm{ii}}$ distance of neighboring copper atoms is 4.731(1) $\AA$. These pairs of supramolecular synthons (Bernstein et al., 1995) $R_{2}{ }^{2}(10)$ and $R_{2}{ }^{2}(12)$ form supramolecular dimmers from complex molecules (2) which are to those found in monomeric complex $\left[\mathrm{Cu}\left(3-\mathrm{NO}_{2} \mathrm{bz}\right)_{2}(\right.$ nia $\left.)\left(\mathrm{H}_{2} \mathrm{O}\right)_{2}\right]$ (nia = nicotinamide, $3-\mathrm{NO}_{2} \mathrm{bz}=3$-nitrobenzoate) with

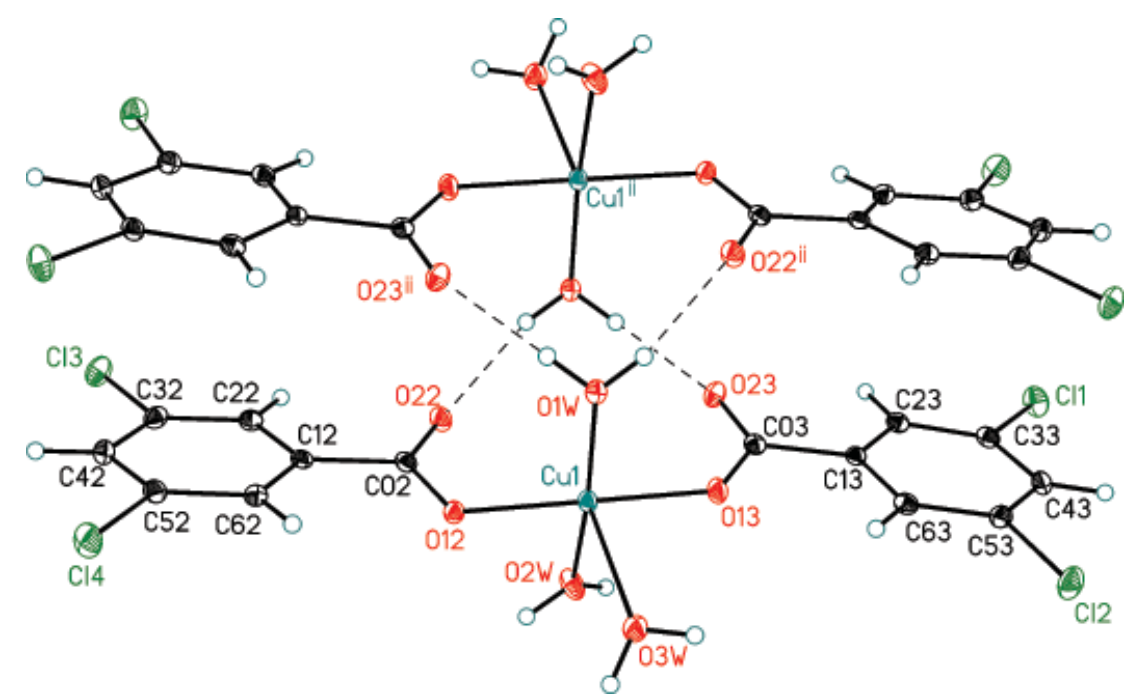

Fig. 2. Perspective view of $\mathbf{2}$, with the atom numbering scheme. Thermal ellipsoids are drawn at the $30 \%$ probability level.

[Symmetry code: (ii) $-x+1,-y+1,-z+2]$. 
Table 3. Hydrogen-bond geometry ( $(\stackrel{\circ}{\circ})$.

\begin{tabular}{|c|c|c|c|c|}
\hline$D-\mathrm{H} \cdots A$ & $D-\mathrm{H}(\AA)$ & $\mathrm{H} \cdots A(\AA)$ & $D \cdots A(\AA)$ & $D-\mathrm{H} \cdots A\left(^{\circ}\right)$ \\
\hline \multicolumn{5}{|c|}{1} \\
\hline O1W-H1W . O 4 iii & 0.84 & 2.41 & $3.028(3)$ & 131 \\
\hline $\mathrm{O} 1 \mathrm{~W}-\mathrm{H} 1 \mathrm{~W} \cdot \mathrm{C}$ Cl2iii & 0.84 & 2.54 & $3.333(2)$ & 158 \\
\hline $\mathrm{O} 1 \mathrm{~W}-\mathrm{H} 2 \mathrm{~W} \cdots \mathrm{O} 2 \mathrm{iii}$ & 0.84 & 2.04 & $2.827(3)$ & 156 \\
\hline \multicolumn{5}{|c|}{2} \\
\hline $\mathrm{O} 1 \mathrm{~W}-\mathrm{H} 1 \mathrm{~W} \cdot \mathrm{O} \mathrm{O} 22 \mathrm{ii}$ & 0.84 & 1.96 & $2.784(2)$ & 167 \\
\hline $\mathrm{O} 1 \mathrm{~W}-\mathrm{H} 2 \mathrm{~W} \cdots \mathrm{O} 23 \mathrm{ii}$ & 0.84 & 1.86 & $2.703(2)$ & 178 \\
\hline $\mathrm{O} 2 \mathrm{~W}-\mathrm{H} 3 \mathrm{~W} \cdots \mathrm{O} 23 \mathrm{iv}$ & 0.84 & 1.90 & $2.725(2)$ & 168 \\
\hline $\mathrm{O} 2 \mathrm{~W}-\mathrm{H} 4 \mathrm{~W} \cdots \mathrm{O} 12 \mathrm{v}$ & 0.84 & 1.89 & $2.724(2)$ & 175 \\
\hline O3W-H6W . O O22iv & 0.84 & 2.18 & $2.999(2)$ & 164 \\
\hline
\end{tabular}

Symmetry codes: (ii) $-x+1,-y+1,-z+2$; (iii) $x-1, y, z$; (iv) $-x+1, y+1 / 2,-z+3 / 2$; (v) - $-x+1, y-1 / 2,-z+3 / 2$.

tetragonal-pyramidal coordination of copper(II) atoms (Vaskova et al., 2010). The molecules of [Cu(3$\left.\left.\mathrm{NO}_{2} \mathrm{bz}\right)_{2}(\mathrm{nia})\left(\mathrm{H}_{2} \mathrm{O}\right)_{2}\right]$ are connected through similar $\mathrm{O}-\mathrm{H} \cdots \mathrm{O}$ hydrogen bonds into supramolecular dimmers, which are shown weak anti-ferromagnetic interactions (Vaskova et al., 2010). The O-H . . O hydrogen bonds in supramolecular dimmers of $\mathbf{2}$ are enriched by $\pi-\pi$ stacking interactions (Janiak, 2000) between two 3,5-dichlorobenzoate ligands. The distances between two benzene ring are in the range 3.3-3.8 $\AA$ (Fig. 3) and $c_{\mathrm{g}} \cdots \mathrm{c}_{\mathrm{g}}$ distance (Janiak, 2000) is $4.17 \AA$. The similar supramolecular synthons $R_{2}{ }^{2}(10)$ and $R_{2}{ }^{2}(12)$ (Bernstein et al., 1995) have been also observed in crystal structure of one dinuclear complex (Valigura et al., 2006) and several polymeric complexes (Abourahma et al., 2002; Burrows et al., 2008; Cao et al., 2008; Korabik et al., 2011; Maharramov et al., 2012; Vaskova et al., 2011; Xu et al., 2007; Yamada et al., 1998).

The crystal packing of $\mathbf{1}$ is shown in Fig. 3. The complex molecules of $\mathbf{1}$ are connected through $\mathrm{O}-\mathrm{H} \cdots \mathrm{O}$ hydrogen bonds between coordinated water molecule (O1W) and carboxylate oxygen atoms of neighboring complex molecules $\left[\mathrm{O} 1 \mathrm{~W}-\mathrm{H} 1 \mathrm{~W} \cdots \mathrm{O} 4^{\mathrm{iii}}\right.$ and O1W-H2W ...O2 2iii (Symmetry code: (iii) $x-1, y, z$ ) with $\mathrm{O} \cdots \mathrm{O}$ distances of 3.028(3) and 2.827(3) Å, re- spectively] (Table 3) into 1-D supramolecular chain in the $z$ axis (Fig. 3). The $\mathrm{O} 1 \mathrm{~W}-\mathrm{H} 1 \mathrm{~W} \cdots \mathrm{O} 4^{\mathrm{iii}}$ hydrogen bond is also supplemented by $\mathrm{O} 1 \mathrm{~W}-\mathrm{H} 1 \mathrm{~W} \cdot \mathrm{Cl} 2^{\mathrm{iii}}$ [O . . Cl distances is 3.333(2) $\AA$ ] hydrogen bond (Table 3) and both ones form multicentered hydrogen bonds system (Desiraju \& Steiner, 1999; Jeffrey, 1997; Gilli \& Gilli, 2009).

The supramolecular dimmers of complex $\mathbf{2}$ are linked through next $\mathrm{O}-\mathrm{H} \ldots \mathrm{O}$ hydrogen bonds between coordinated water molecules and carboxylate oxygen atoms $\left[\mathrm{O} 2 \mathrm{~W}-\mathrm{H} 3 \mathrm{~W} \cdots \mathrm{O} 23^{\mathrm{iv}}\right.$; $\mathrm{O} 2 \mathrm{~W}-\mathrm{H} 4 \mathrm{~W} \cdots \mathrm{O} 12^{\mathrm{v}}$, and $\mathrm{O} 3 \mathrm{~W}-\mathrm{H} 6 \mathrm{~W} \cdots \mathrm{O} 22^{\mathrm{iv}}$ (Symmetry codes: (iv) $-x+1, y+1 / 2,-z+3 / 2$; (v) $-x+1$, $y-1 / 2,-z+3 / 2)$ with $\mathrm{O} \ldots \mathrm{O}$ distances of $2.725(2)$; 2.724(2) and 2.999(2) A, respectively] (Table 3) forming 2-D framework in $b c$ plane (Fig. 4). The $\pi-\pi$ stacking interactions (Janiak, 2000) between two 3,5-dichlorobenzoate ligands are also observed between two supramolecular dimmers (Fig. 5). The distances between two benzene rings (between two supramolecular dimmers) are in the range 3.18-3.50 A (Fig. 3) and $c_{g} \cdots c_{g}$ distance (Janiak, 2000) is $3.61 \AA$.

Both studied complexes have been prepared similar method, but this method is different that published methods of synthesis of complex $\mathbf{1}$ (Kawata et al.,

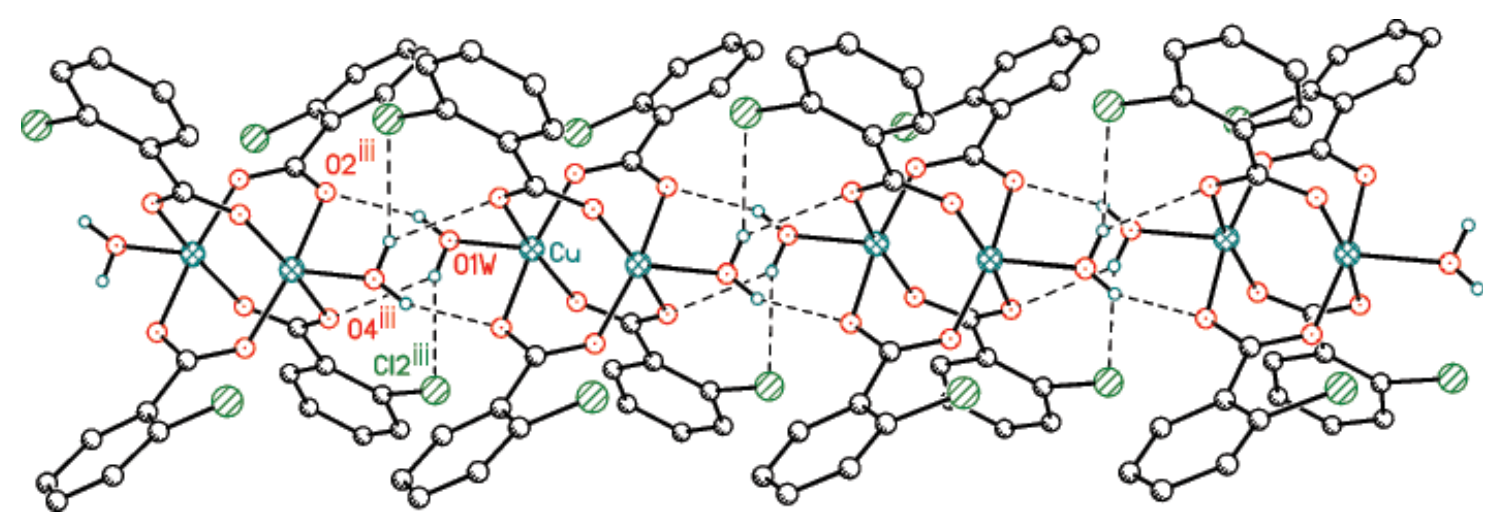

Fig. 3. The two 1-D chains connecting through $\mathrm{O}-\mathrm{H} \cdots \mathrm{O}$ and $\mathrm{O}-\mathrm{H} \cdots \mathrm{Cl}$ hydrogen bond in crystal structure of $\mathbf{1}$. [Symmetry code: (iii) $x-1, y, z$ ]. 


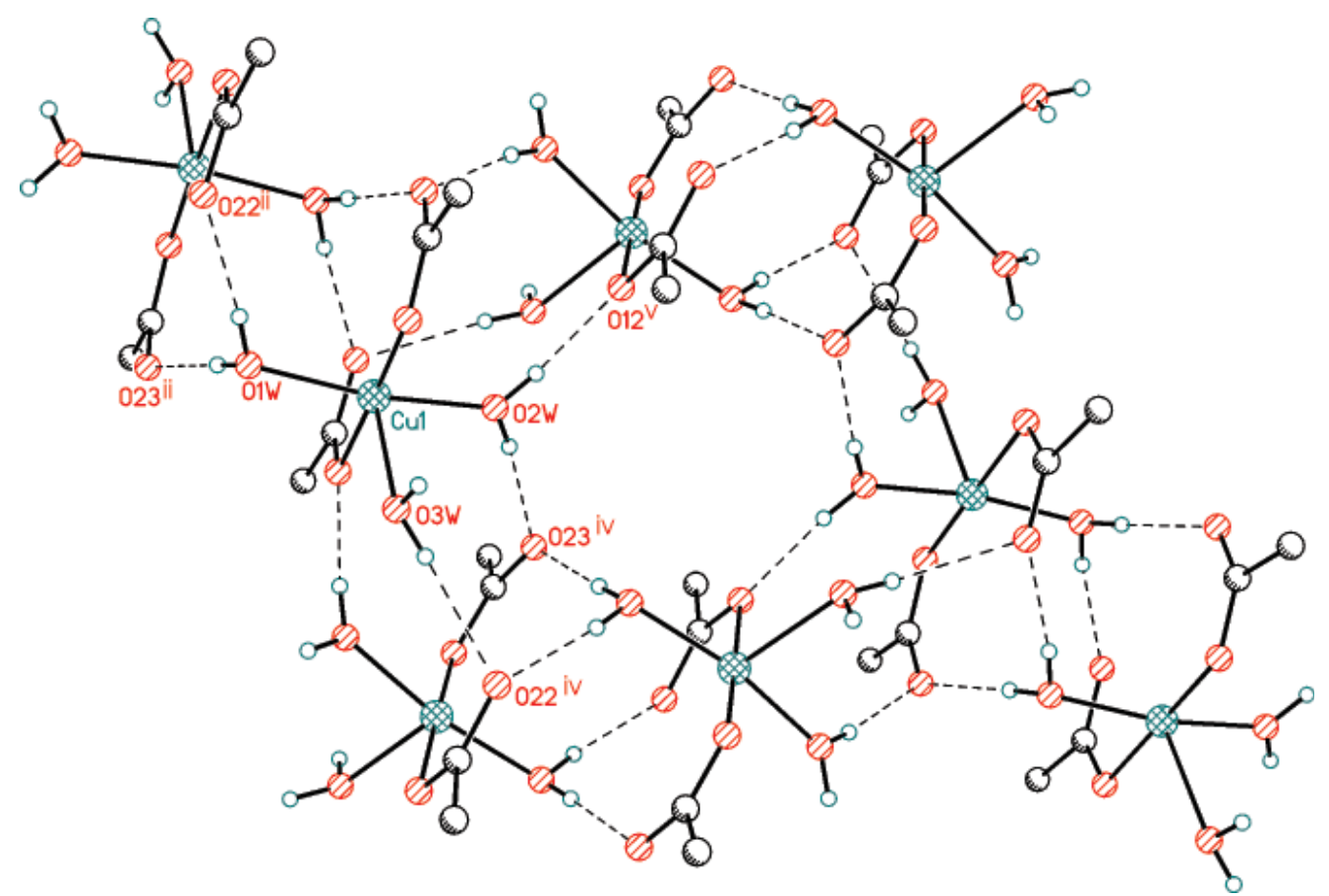

Fig. 4. The 2-D framework connecting through $\mathrm{O}-\mathrm{H} \cdots \mathrm{O}$ hydrogen bond in crystal structure of 2. The benzene rings and chlorine atoms are omitted for clarity.

[Symmetry codes: (ii) $-x+1,-y+1,-z+2$; (iv) $-x+1, y+1 / 2,-z+3 / 2$; (v) $-x+1, y-1 / 2,-z+3 / 2$ ].

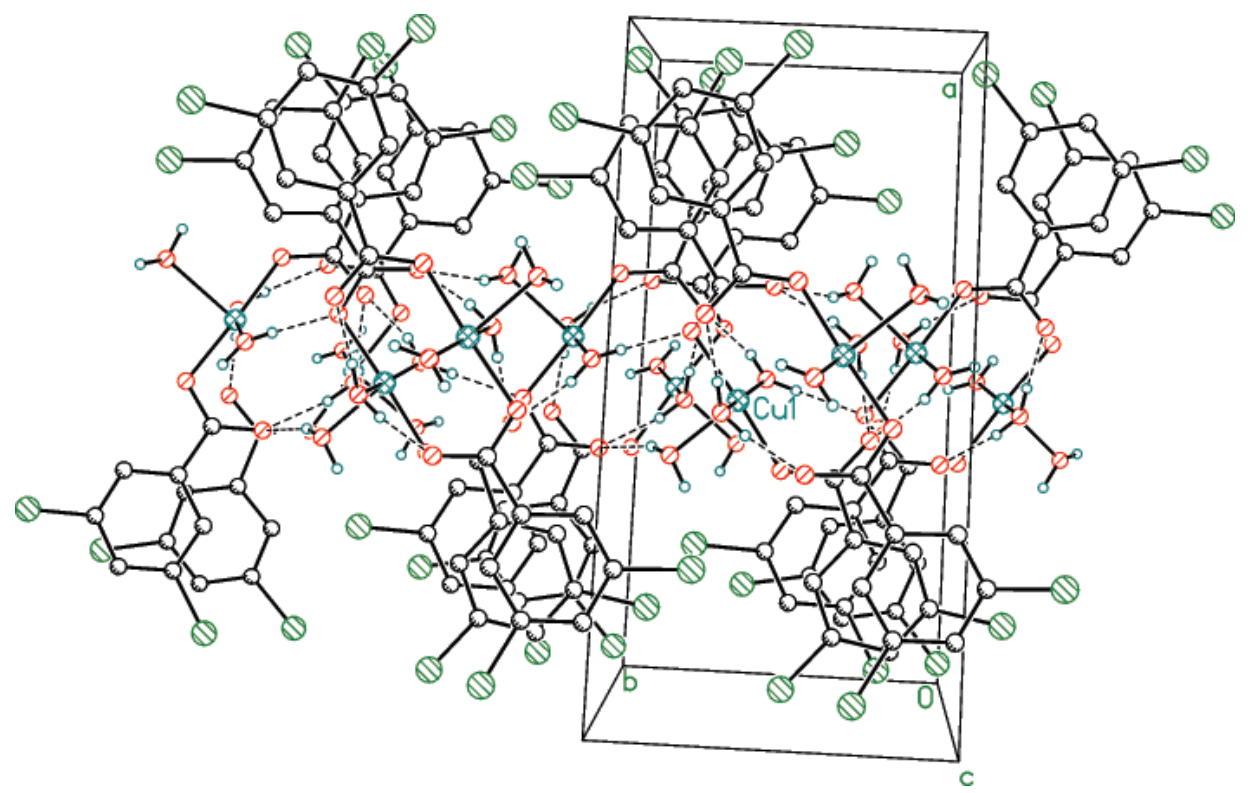

Fig. 5. The $\pi-\pi$ stacking interactions in crystal structure of $\mathbf{2}$.

1992) or 2 (Wołodkiewicz et al., 1998). The structures of both complexes have been determinated at room temperature, but hydrogen atoms have not been calculated in corrected positions, but Low-temperature re-determination at $150 \mathrm{~K}$ allows determinate more better results and the hydrogen atoms are calculated in correct positions. Novelty in present paper is description of hydrogen bond networks and $\pi-\pi$ stacking interactions in crystal structures of both complexes. The studies of hydrogen bonds and intermolecular interaction have been absent in original room temperature crystal structures (Kawata et al., 1992; Wołodkiewicz et al., 1998).

At the end we would like to pointed out, presence of neutral ligand in reaction mixture lead to formation of complexes without ligand in coordination sphere. They were prepared by different methods 
of syntheses in the past. Re-determined of obtained complexes at $150 \mathrm{~K}$ we specify basic features and parameters and we specify shape of coordination polyeder of known complexes. Description of hydrogen bond networks and $\pi-\pi$ stacking interactions in crystal structures of both complexes have been presented too.

\section{Acknowledgement}

This work was supported by the Scientific Grant Agency of the Ministry of Education of the Slovak Republic (VEGA Project Nos. 1/0856/11 and 1/0562/10) and by the Research and Development Agency of the Slovak Republic (contract No. APVV-0202-10).

\section{References}

Abourahma H, Moulton B, Kravtsov V, Zaworotko MJ (2002) J. Am. Chem. Soc. 124: 9990.

Addison AW, Rao TN, Reedijk J, Rija J, Verchoors GC (1984) J. Chem. Soc. Dalton Trans. pp. 1349.

Altomare A, Burla MC, Camalli M, Cascarano GL, Giacovazzo C, Guagliardi A, Moliterni AGG, Polidori G, Spagna R (1999) J. Appl. Cryst. 32: 115.

Bernstein J, Davis RE, Shimoni L, Chang NL (1995) Angew. Chem., Int. Ed. Engl. 34: 1555.

Bruker (2008) APEX2, SAINT-Plus and SADABS. Bruker AXC Inc., Madison, Wisconsin, USA.

Burrows AD, Frost CG, Mahon MF, Winsper M, Richardson C, Attfield JP, Rodgers JA (2008) Dalton Trans. pp.6788.

Cao R, Lu J, Batten SR (2008) CrystEngComm 10: 784.

Desiraju GR, Steiner T (1999) The Weak Hydrogen Bonds and in Structural Chemistry and Biology, Oxford University Press, Oxford, UK.
Janiak C (2000) J. Chem. Soc., Dalton Trans. pp. 3885.

Jeffrey GA (1997) An Introduction to Hydrogen Bonding, Oxford University Press, Oxford, UK.

Kawata T, Ohba S, Tokii T, Muto Y, Kato M (1992) Acta Cryst. C48: 1590.

Korabik M, Repicka Z, Martiska L, Moncol J, Svorec J, Padelkova Z, Lis T, Mazur M, Valigura D (2011) Z. Anorg. Allg. Chem. 637: 224.

Gilli G, Gilli P (2009) The Nature of the Hydrogen Bond, Oxford University Press, Oxford, UK.

Maharramov AM, Mardanova VI, Chyraqov FM, Gurbanov AV, Ng SW (2012) Acta Cryst. E68: m128.

Melnik M, Kabesova M, Koman M, Macaskova L, Garaj J, Holloway CE, Valent A (1998) J. Coord. Chem. 45: 147.

Sheldrick GM (2008) Acta Cryst. A64: 112.

Sorenson JRJ (1976) J. Med. Chem. 19: 135.

Sundberg MR, Uggla R, Melnik M (1996) Polyhedron 15: 1157.

Valigura D, Moncol J, Korabik M, Pucekova Z, Lis T, Mrozinski J, Melnik M (2006) Eur. J. Inorg. Chem. pp. 3813.

Vaskova Z, Moncol J, Korabik M, Valigura D, Svorec J, Lis T, Valko M, Melnik M (2010) Polyhedron 29: 154.

Vaskova Z, Moncol J, Korabik M, Medvecka J, Svorec J, Padelkova Z, Valko M, Valigura D (2011) Polyhedron 30: 86.

Weder JE, Dillon CT, Hambley TW, Kennedy BJ, Lay PA, Biffin JR, Regtop HL, Davies N M (2002) Coord. Chem. Rev. 232: 95.

Wołodkiewicz W, Brzyska W, Głowiak T (1998) Monatsh. Chem. 129: 111.

Xu JY, Chen BL, Ng SW (2007) Acta Cryst. E63: m2200. Yamada Y, Ueyama N, Okamura T, Mori W, Nakamura A (1998) Inorg. Chim. Acta 275-276: 43. 